\title{
El interminable proceso de democratización en México. Un breve análisis histórico del árbitro electoral
}

\section{The endless process of democratization in Mexico. A brief historical analysis of the electoral referee}

\author{
Dr. José Cisneros Espinosa \\ Benemérita Universidad Autónoma de Puebla México. \\ ulises33@yahoo.com \\ https://orcid.org/0000-0001-8114-3051 \\ Dr. Alejandro Silva Arias \\ RAMADASA SA de CV, Colombia \\ https://orcid.org/0000-0003-1158-4809 \\ Dr. José Antonio Cisneros Tirado \\ Benemérita Universidad Autónoma de Puebla México. \\ joseantonio.cisneros@correo.buap.mx \\ https://orcid.org/0000-0002-8825-5467 \\ Recepción: 9/11/2020 Revisión: 18/11/2020 \\ Aceptación: 17/12/2020 Publicación: 27/12/2020
}

\section{Resumen}

En México, a dos décadas del triunfo de un partido político diferente al PRI en las elecciones presidenciales del año 2000, tiempo en el que muchos analistas políticos empezaron a hablar de una "transición a la democracia", asumiendo implícitamente que en las décadas anteriores no la había habido, y, una vez más, con la derrota de los dos partidos principales PRI y PAN en las elecciones de 2018 por parte del Movimiento de Regeneración Nacional (MORENA), el presente artículo tiene como finalidad hacer un breve análisis del proceso de democratización electoral en el país. Para ello se propone responder preguntas como las siguientes: ¿Realmente se transitó a la democracia? ¿La participación ciudadana se hizo sentir en las decisiones de gobierno del año 2000 a 2018? ¿El instituto responsable de organizar las elecciones y dar los resultados oficiales se ganó la confianza y la credibilidad de la población?

Dado lo extenso del tema, en este trabajo nos enfocamos principalmente en analizar el desempeño del Instituto Federal Electoral (IFE), luego Instituto Nacional Electoral (INE), a lo largo de este tiempo, en tanto que representa la posición oficial de la democracia electoral en México, pero sin dejar de abordar el contexto político-económico del manejo de la democracia en nuestro país de 1946 a 2020.

En primer lugar se presenta un marco conceptual general sobre la democracia y el árbitro electoral, para luego analizar el desempeño del árbitro electoral en México como parte central del texto, y se finaliza con una reflexión sobre el futuro de la democracia en nuestro país.

\begin{abstract}
On the year 2000, after 80 years of a single-party by the PRI, a different political organization won the Mexican presidential elections, with many political analysts labelling this phenomenon as a "democratic transition"; thus implying this was the first democratic government ruling the country after many decades of a state-party system of government. In 2018, a new political movement, known as the National Regeneration Party Movement (MORENA) defeated both the PRI and PAN as mainstream, historical parties. This article focuses on analyzing this electoral democratization process in Mexico. Hence, the following questions are posed for discussion: Did Mexico actually moved towards democracy in 2000? Did citizen participation have an impact in governmental decisions from 2000 to 2018? Did the National Electoral Institute (INE in Spanish), as the organization responsible of organizing and providing official results, earn nationwide credibility from citizens regarding these processes?

Considering the comprehensive time span of this phenomena, the scope of this article is analyzing the performance of the National Electoral Institute in these political processes, as it represents the official
\end{abstract}


governmental view of electoral democracy in Mexico. Also, this essay looks at the political and economic context of how democracy has evolved in Mexico during the second half of the twentieth century.

Firstly, we introduce a conceptual framework on democracy and the electoral authority; then we analyze the INE's performance in electoral democracy as the key aspect of this work and we close with some thoughts on the future of Mexican democracy.

Palabras clave: Democracia electoral, árbitro electoral, transición democrática.

Keywords: Electoral democracy, electoral authority, democratic transition.

\section{Introducción}

El presente artículo, en tanto análisis del proceso histórico de la democratización en México, y en particular del comportamiento del árbitro electoral, tiene la pretensión de contribuir a la construcción de un marco de referencia político-electoral para la lectura de los artículos elaborados desde la comunicación política incluidos en esta revista. Con dicha finalidad, en este trabajo sólo trazamos una línea temática orientada a dar respuesta a la pregunta sobre el árbitro electoral. Partimos de un principio básico que es la ubicación conceptual de la democracia en la modernidad. A continuación destacamos su carácter imperfecto, y en este plano de análisis centramos nuestra atención en dos aspectos: uno, la acción dramatúrgica (Habermas, 1987), que explica la escenificación como se han hecho históricamente las elecciones en México, en tanto eventos aparentemente democráticos para la población, y dos, concomitante a ello, el papel del árbitro electoral. El árbitro visto como actor político que ha sido renovado constantemente por el régimen sin que a la fecha haya podido lograr la confianza de los electores de manera definitiva.

Planteamos en el desarrollo del texto que estos dos aspectos se explican por la condensación política de intereses económicos y políticos que se fueron estructurando como bloque histórico (Gramsci, 1981; Portelli, 1977) con las políticas de industrialización en México, y que alcanzaron pleno dominio del país durante el llamado periodo neoliberal (1983 - 2018). Finalmente presentamos una perspectiva política acorde al cambio del contexto nacional e internacional, para culminar con una breve reflexión sobre el futuro de la democracia en México.

\section{El marco conceptual}

Modernidad, racionalismo, libertad, individualismo, socialización y democracia, conforman la base conceptual de la visión del mundo capitalista o burguesa, inicialmente europea y después occidental con perspectivas globales. Ninguno de estos conceptos tiene una definición incontrovertible; sin embargo, esto no impide que los intelectuales orgánicos aborden los acontecimientos económicos, políticos, ideológicos y culturales sin cuestionar al sistema en su conjunto. Este es el límite explicativo que tienen sus trabajos académicos y periodísticos. Y es por tal razón que los dirigentes económicos y políticos forjan un mundo basado en el interés económico, la ganancia y el poder, empleando esta concepción social como respaldo.

En esta perspectiva de pensamiento, la modernidad es entendida como la ruptura intelectual respecto al pasado feudal. Es con el advenimiento de la reforma, el renacimiento y la ilustración, que se proclama la superioridad de la razón sobre la fe. La razón ciertamente es subjetiva, propia del individuo que se ve a sí mismo libre de ataduras intelectuales y materiales, con derecho a la crítica y a la autonomía de acción (Habermas, 1993). Pero sobre todo, el individuo se ve libre para crear empresas en busca de la rentabilidad y el beneficio propio, el lucro pacífico. Como diría Max Weber: "La organización racional de la empresa orientada a las oportunidades del mercado, no a la especulación irracional o a la fortuna de la violencia política" (Weber, 1997:321) como una aspiración. 
En la modernidad, es el mercado en donde fluyen el individualismo, la empresa y la búsqueda de maximizar las ganancias siguiendo el sentimiento más puro del sistema: el egoísmo, el interés individual en la búsqueda de la riqueza como motivo existencial. Justo lo contrario de la filosofía de los pueblos originarios de Mesoamérica, donde el bien de la comunidad está por encima del interés personal. En la modernidad, además de la ganancia, la competencia en el mercado se convierte en el motor del comportamiento de los propietarios de industrias y comercios que impide una mayor unidad entre ellos, salvo en la búsqueda de mecanismos que les permitan obtener mayores ganancias de grupo, o entre los más lúcidos, realizar acciones para la preservación del sistema que tan gratos frutos les proporciona (Chen, 2020).

En el mundo moderno se concibe a la preservación del sistema como una obligación del estado, emanado de una constitución política donde la propiedad privada es sagrada, el derecho y la administración son racionales, todos los ciudadanos son iguales ante la ley y pueden votar y ser votados para conformar un sistema político democrático y representativo. Así, la democracia en sus orígenes modernos privilegió a los poseedores, hombres ricos y poderosos, y sólo avanzó por la exigencia, muchas veces violenta, de los subalternos (Kates, 2011).

La supremacía existencial del individuo, y con él del ciudadano, distrae la concepción original de pueblo en tanto comunidad, verdadero forjador de las revoluciones burguesas y el proceso democrático. El pueblo poli clasista fue quien derrotó a la aristocracia. La nueva clase dominante, la burguesía, prefirió separarse de las clases subalternas y tacharlas de populismo para transar con el sistema monárquico y crear los sistemas monárquico-parlamentarios.

Individualismo y sociedad en la concepción burguesa están mediados por la socialización dentro de ese horizonte; socialización entendida como el conjunto de procesos necesarios para la existencia individual y la convivencia social, tales como la educación, la iglesia, el comercio, etc. El estado es democrático en cuanto los individuos, libres, racionales, ciudadanos, emiten a través de un proceso de socialización política su voto para elegir gobierno, el cual dirigirá y administrará los asuntos de todos los individuos en su conjunto, es decir, de la sociedad (Kates, 2011).

La democracia es racional y por lo tanto es real, diría René Descartes. Sin embargo, la historia nos dice que la democracia moderna que nació en Inglaterra con el parlamento, terminó pactando con la monarquía irracional del viejo régimen. Estados Unidos como nación, considerado el paradigma de la democracia moderna, nació excluyendo irracionalmente a los poseedores originarios del territorio. Y también a los esclavos negros; ellos ya no eran libres, ni los consideraban racionales, ni ciudadanos, sólo fuerza de trabajo. La democracia francesa, nacida de la revolución, siguió un camino errático que no se consolidó hasta después de la Segunda Guerra Mundial. No obstante, el ideal francés se convirtió en el faro político del mundo que aún sigue inspirando la libertad, la igualdad y la fraternidad (Doyle, 2018).

La democracia moderna nació entonces empotrada en la monarquía de Inglaterra, y ese modelo mixto ha sobrevivido hasta nuestros días, no sólo ahí, sino también en varios países europeos y en Japón; aunque hoy la mayoría de los monarcas, si bien nominalmente figuran como jefes de Estado, su papel es más simbólico que real, pues el Primer ministro es quien mantiene la jefatura del gobierno y obtiene su puesto democráticamente.

La democracia como forma de estado sólo se impuso en el llamado mundo occidental después de la Segunda Guerra Mundial, bajo la égida de la hegemonía norteamericana acorazada de coerción. En el caso de Latinoamérica, con excepción de México, los estados han estado oscilando entre democracia y dictaduras militares, de acuerdo con los intereses norteamericanos y los pactos con los grupos económicos y políticos nacionales preponderantes (Lewis, 2006).

En la realidad, la democracia como organización de la sociedad política dista mucho de ser general, y existe una gran diferencia entre la concepción ideológica que se tiene de ella y la forma operativa como se desarrolla en la práctica. 
La democracia que opera actualmente en la mayoría de los estados de acuerdo a sus constituciones, es representativa. Los muchos se representan en pocos, aquellos que son elegidos por medio del sufragio y sobre los cuales es delegada la soberanía. Éstos conformarán, según el régimen prevaleciente, los poderes como el ejecutivo y el legislativo. El poder judicial no se elige democráticamente. Los representantes, en la mayoría de los casos, actuarán más por motu propio que en atención a los compromisos adquiridos con sus representados durante las campañas electorales. Y es aquí donde radica la importancia de la conformación de los poderes. Pues aunque el proceso electoral parece una actividad simple que redundará en beneficio de los electores, no lo es, pues se ponen en juego una serie de estrategias para violentar la voluntad del electorado por parte de sus representantes, tales como la violencia, la dramaturgia política, las campañas negras y la corrupción.

De acuerdo a clasificaciones elaboradas por The Economist, Intelligence Unit (2019) tomando en consideración 167 países, establece cuatro tipos de régimen: "democracia plena", "democracia defectuosa o imperfecta", "régimen híbrido" y "régimen autoritario". Para ello pondera cinco categorías: proceso electoral y pluralismo, libertades civiles, el funcionamiento del gobierno, participación política y cultura política. Reconoce que sólo una veintena de países tiene una democracia plena que comprende apenas el $4.5 \%$ de la población mundial, y 90 países viven en un régimen no democrático. Lo cual demuestra que la democracia realmente existente en el mundo sigue siendo una tarea en curso.

\subsection{La democracia imperfecta}

En la clasificación que antes hemos citado, México aparece en los últimos lugares de la democracia defectuosa o imperfecta, casi a punto de ser considerado como un régimen híbrido. Es decir, no democrático. Eso se explica fundamentalmente en el análisis por la baja calificación que se le otorga en el rubro de cultura política, obteniendo una calificación aprobatoria en los otros aspectos.

Esto puede entenderse de la siguiente manera: si bien es cierto que en el interminable proceso de democratización de México se ha avanzado en los aspectos formales que incluyen las leyes y las instituciones públicas que les atañen, esto no se corresponde, hasta antes de 2018, con el comportamiento ciudadano caracterizado por la apatía, el desinterés y la desconfianza. Dicho comportamiento, a su vez, obedece a un mala relación dialéctica entre gobernantes y gobernados, entre representantes y representados, que se ha dado a través de la historia política. Así, si bien es cierto que en apariencia el país da la imagen de un país democrático, en la realidad los ciudadanos experimentan algo muy diferente, como el temor ante los múltiples hechos de represión que han vivido y muestran su impotencia (Murillo, 1990); aceptan la representación electoral, por ejemplo, pero se ausentan de este proceso a través del abstencionismo (Bobbio et al., 2005: 8), y mantienen la desconfianza tanto en los procesos electorales como en la democracia en general.

En este contexto político el gobierno recurre generalmente a lo que Jürgen Habermas (1987) conceptualiza como acción dramatúrgica. Por acción dramatúrgica se entiende la interacción entre un agente o actor que hace presentación de sí mismo (un político o el INE), y un grupo social que se constituye en público (los electores). El actor suscita en su público una determinada imagen, una determinada impresión de sí, revelando su subjetividad de forma más o menos calculada con miras a esa imagen que de sí quiere dar.

La acción dramatúrgica está dirigida a un público que, sin percatarse de las intenciones estratégicas del actor-emisor para lograr sus propios fines, se imagina estar asistiendo a una representación orientada al entendimiento. Es decir, la acción estratégica en general, implica una relación asimétrica en la cual uno de los participantes (actor, emisor) establece los fines, define 
los argumentos, y planea su comportamiento para con-vencer a su oponente racional (elector) de que tome una determinada decisión que beneficia al primero (Habermas, 1987).

En otras palabras, podemos considerar la acción dramatúrgica en política como un arte complejo de auto-representación, cuyo objetivo fundamental es que la audiencia o el público crea que las cosas sucedieron de una manera, cuando quien realizó el montaje sabe muy bien que no fue así. La acción dramatúrgica es una acción estratégica del emisor.

La acción dramatúrgica como proceso operativo, requiere perfeccionamiento; es decir, la supresión progresiva de los errores que han sido evidentes al público, y que éste descubre y señala. Una vez que esto sucede, por ejemplo, en el caso de un estratega electoral, éste debe innovar con trucos escenográficos nuevos y cada vez más sofisticados para que la dramaturgia resulte creíble. Esto es lo que en México se le ha llamado coloquialmente como "alquimia electoral", y lo que en el caso del INE han significado sus sucesivas reformas.

El guion básico de la escenificación política es aparentar que se cumple lo necesario con la ley, con la norma vigente y con los procedimientos; que las violaciones observadas y denunciadas son justificadas, minimizadas o procesadas, y que los observadores sociales de oficio (medios de difusión) dan por válido el proceso.

De esta manera, la acción dramatúrgica política es un acto de poder con el objetivo de mantener el poder. Requiere de la acción concertada de todos los actores involucrados por el emisor, cuya gestión racional los llevará a maximizar sus beneficios. Por ello, su comportamiento estará mediado por las ganancias y la garantía de que recibirán lo prometido, y aún más de lo prometido, pero sobre todo que serán impunes. No puede haber fisuras en el manejo de la información o comportamientos fuera de contexto que pudiesen poner en riesgo la credibilidad. La confianza en el proceder de los actores es vital para el aseguramiento de su éxito. Sobre todo en actos de espectro tan amplio como es el caso de un fraude electoral.

La acción dramatúrgica, pues, ya en escena, tiene el propósito fundamental de convencer a la audiencia de que lo que está viendo y viviendo es la realidad inobjetable. El engaño se introduce en el mundo subjetivo y se asocia a los sentimientos de la audiencia para que el engañado mitigue su desconfianza o su inconformidad. Los que se resisten al engaño, los que lo denuncian, se enfrentan a un entorno violento de las fuentes del poder que conjuga la descalificación, la burla, la difamación, el encono, la violencia, e incluso la encarcelación en contra de ellos.

La dramaturgia democrática electoral, entonces, está encaminada a crear o mantener la confianza en los procesos electorales. Y uno de los aspectos esenciales de la democracia es la confianza que deben tener los partidos políticos y los ciudadanos de que las elecciones en las que participan o han participado han sido libres, justas y limpias; es decir, que no existió intervención externa a los actores implicados en el proceso electoral. Pues ahí donde existe desconfianza, los ciudadanos se alejan de la participación electoral y predomina el ausentismo y los votos nulos. En otros casos, se suceden las protestas de inconformidad o manifestaciones violentas de rechazo a los resultados de las votaciones, y la democracia se vuelve opaca (Habermas, 2014).

\subsection{El árbitro en la democracia electoral}

En una democracia plena, el árbitro electoral no es tan relevante ni en el proceso ni en el resultado de las elecciones. No importa si es el mismo gobierno el que organiza el proceso, o si es independiente o mixto. Así se muestra en el Handbook on Electoral Management Design (2014), que con base en criterios de independencia y funciones esenciales, tales como el registro de candidaturas, la recepción y conteo de votos entre otras, que pueden incluir el registro de electores, el diseño de la geografía electoral y, en su caso, la justicia electoral o lo contencioso 
electoral, ha establecido tres tipos de modelo de gestión electoral: el independiente, el mixto y el gubernamental.

Si relacionamos los indicadores de democracia que nos ofrece The Economist Intelligence Unit (2019) (Proceso electoral y pluralismo, Funcionamiento del gobierno, Participación política, Cultura política, y Libertades civiles) con las formas de gestión electoral del Handbook on Electoral Management Design (2014) (Democracia plena, Democracia defectuosa, Régimen híbrido y Régimen autoritario), podemos ver que de los 20 países con democracia plena, 10 tienen el modelo gubernamental, 9 el modelo independiente y 1 el mixto. De acuerdo con esto podemos observar que el hecho de que el organismo electoral sea independiente no garantiza un valor democrático, sino que la buena reputación sólo se alcanza en el largo plazo y observando cómo resuelve los casos difíciles planteados por los mismos procesos electorales. Incluso un modelo gubernamental puede retroalimentarse a sí mismo en términos de confianza, si es capaz de cumplir eficiente y limpiamente con sus tareas electorales, sin simulación ni engaño que ponga en duda su actuación.

En el caso de México, que actualmente cuenta con el modelo independiente, que ocupa el lugar 52 de 55 de los países con democracia imperfecta o defectuosa, y el lugar 71 de 75 (The Economist, Intelligence Unit, 2019), si tomamos juntos tanto los de democracia plena y como los de democracia imperfecta, las cosas son diferentes. Aquí, dada la experiencia y el conocimiento de los actores políticos, la creencia de los ciudadanos es que el árbitro es fundamental para el proceso democrático electoral. Se espera que él sea confiable, eficiente y responsable en la medida en que su actuación determinará la legitimidad del resultado de las elecciones, y, por tanto, el rumbo político de la nación. La democracia se consolida cuando hay confianza de los electores y los partidos en el árbitro y en el proceso electoral; es decir, en la gestión, control y justicia electorales. Esto es un factor decisivo de legitimidad. Por el contrario, si hay desconfianza en el árbitro, en el proceso y en los resultados, no sólo se ausenta la legitimidad, sino que se aplica la dramaturgia política, se encubre el autoritarismo y se posibilita el fraude.

\section{El marco contextual e histórico del árbitro electoral en México}

Al hacer una somera revisión de los mecanismos de designación y el comportamiento del árbitro electoral en las elecciones presidenciales de México, podemos observar cómo se presenta lo expuesto anteriormente, en un claro contraste entre el descrédito del árbitro, la ausencia de democracia plena, y la aspiración de la mayoría de los mexicanos a que se cumpla adecuadamente con estas tareas políticas.

El punto de partida de esta revisión lo hemos establecido en 1946, el momento en que el partido de estado y el gobierno iniciaron un proceso prolongado de transición en pos de la democracia del país, la industrialización y la modernización en el mundo de la posguerra. Dos elementos han modulado el proceso en este trayecto. Por un lado, las constantes presiones directas e indirectas por parte del gobierno de Estados Unidos, a veces en favor, a veces en contra, dependiendo de sus intereses de cada momento. Y por el otro lado, los brotes de inconformidad nacionales que ya no puede contener o negociar la estructura de cacicazgos regionales y nacionales propios del sistema. A esto podríamos agregar un tercer factor ideológico: la influencia de las tendencias políticas internacionales proveniente de los países desarrollados que seducen a la intelectualidad nacional urbana (Cosío-Villegas, 1985).

En este trance de búsqueda de legitimidad sin perder el control político, acorde a los intereses del bloque histórico en el poder, el proceso democrático formal no implicaba necesariamente la realización de elecciones limpias, transparentes y creíbles, sino una estrategia gradualista que fuese cediendo lo necesario, basada en la simulación dramatúrgica, y por lo tanto 
permanentemente sospechosa y desconfiable, que se mantendría por la fuerza misma del poder hasta donde fuese posible (Cisneros, 2015).

Para que esta dramaturgia pudiese llevarse a cabo, se requería, entre otras cosas, el control del proceso electoral a través de un árbitro que gestionara adecuadamente todas las irregularidades y opacidades que se presentasen. La mejor fórmula sin duda era, como sucedía en muchos países, que el propio gobierno se encargase de las elecciones; es decir, ser juez y parte hasta donde las condiciones internacionales y nacionales lo permitiesen en un país en dónde el partido oficial y el estado eran indistinguibles. Luego, conforme se fuese agotando este modelo de simulación democrática, se iniciaría un largo proceso de desvinculación de los organismos electorales hasta llegar a su autonomía. Es decir, serían parte del estado, pero independientes del gobierno.

Por su parte, las elecciones de 1946 tenían varios significados en la vida política del país. En ese año, el Partido de la Revolución Mexicana (PRM) se convertía en el Partido Revolucionario Institucional (PRI), y su primer candidato ya no era más un general, sino uno civil, el Licenciado Miguel Alemán Valdés, Secretario de Gobernación del General Manuel Ávila Camacho, quien planteaba la modernización del país pero sin abandonar la justicia social, valor fundamental heredado de la Revolución Mexicana. (Reyna, José Luis, 1993).

En las elecciones de ese año se estrenaba la recién promulgada Ley Federal Electoral y la creación de la Comisión Federal de Vigilancia Electoral, que estaba conformada por el Secretario de Gobernación (PRI), un miembro del gabinete (PRI), un diputado (PRI), un senador (PRI) y dos representantes de los partidos políticos de mayor relevancia, PRI y otro. Es decir, el control político estaba en manos del PRI. No sólo eso, Por primera vez en la historia, la preparación, vigilancia y desarrollo del proceso electoral quedaba bajo la responsabilidad del gobierno federal, es decir, de la presidencia de la república, dejando a un lado a gobernadores y presidentes municipales; entiéndase, a caciques locales y regionales.

Los resultados electorales fueron los esperados por el árbitro-gobierno: votaron 1, 786,901 personas. Por el candidato del PRI a la presidencia lo hicieron el $77.9 \%$; pero además, el PRI obtuvo 141 de 147 diputados posibles, y todos los 58 senadores que estaban en disputa.

Ya en la presidencia, Miguel Alemán apresuró el proceso de industrialización del país favoreciendo de manera especial a los hombres de negocios, incluso él se convirtió en uno de ellos siendo el Presidente de la República. La corrupción, el enriquecimiento del sector empresarial a costa del estado, y las pretensiones de reelección de Miguel Alemán, no sólo generaron descontento en el pueblo, también en sectores importantes del partido en el poder. Particularmente en el grupo de los generales del ejército (Cosío-Villegas, 1985).

Previo a la elección de Adolfo Ruiz Cortines, se reformó La Ley Federal Electoral, entre otras cosas, para dar más realce al árbitro electoral. La Comisión Federal de Vigilancia Electoral dio paso Comisión Federal Electoral. En ella sólo quedó un comisionado del poder ejecutivo que era el Secretario de Gobernación, y se aumentó a tres el número de los representantes de los partidos políticos (Haddad, 2001).

El juego de la democracia se volvió pronto en contra del régimen. El candidato por el Partido Constitucionalista Mexicano y la Federación de Partidos del Pueblo Mexicano, el general Miguel Henríquez Guzmán, puso en relativo riesgo la sucesión presidencial. Entonces el régimen recurrió, como lo había hecho en 1929, a lo que más tarde serían sus armas electorales características para garantizar la sucesión presidencial. Estableció una estricta vigilancia militar, impidió el acceso a los representantes de la oposición a las mesas de las casillas, rellenó urnas, falsificó actas y contabilizó los votos como quiso. Con estas acciones el mensaje era claro y contundente: las elecciones eran para legitimar el poder del régimen, no para ponerlo en juego. De esta manera, en 1952 el candidato del PRI, el Contador Adolfo Ruiz Cortines, obtuvo el 74.31\% de la votación y el General Miguel Enríquez Guzmán sólo el 15.88\% (Servín, 2002). 
A partir de entonces, la clase política entendió muy bien el mensaje y el pueblo experimentó la realidad política. No habría mayores cambios ni en el proceso electoral ni en su organismo arbitral, hasta el día 28 de diciembre de 1977, cuando se expidió La Ley de Organizaciones Políticas y Procesos Electorales (LOPPE) (Méndez de Hoyos, 2006).

La carga del movimiento estudiantil de 1968, la alerta guerrillera y el descontento social producto de la crisis de 1974 -75, hacían necesaria la apertura de la válvula electoral. Así lo entendió también el presidente de entonces José López Portillo (1976-1982). Quizás el hecho más importante que sopesó el presidente fue que él mismo había ganado las elecciones con el $97.01 \%$ del total de votos (CEDE, s/f), sin contendiente legal al frente. Es decir, fue candidato único. Hecho inaceptable en las llamadas democracias modernas. No sólo eso, hubo cerca de un millón de votos nulos. Evidentemente la simulación de que México transitaba hacia la democracia estaba en plena bancarrota. $\mathrm{Y}$ ante el control autoritario del PRI, se manifestaba entonces un comportamiento político pasivo por parte de la mayoría de la población, asumiendo que los valores de la democracia le eran ajenos y sus expectativas políticas constituían una quimera.

Por tanto, la nueva ley de 1977 abría el paso a la formación y legalización de nuevos partidos políticos. La apertura fue aprovechada por cuatro partidos que se definían de izquierda (PCM, PST, PRT y PMT) y uno de derecha (PDM). Se establecieron prerrogativas y participación proporcional en las Cámaras.

La Comisión Federal Electoral quedó conformada por el infaltable Secretario de Gobernación, un representante de cada una de las cámaras legislativas, un representante de cada partido político con registro, y un notario público. El Secretario de Gobernación se mantuvo en la Comisión como el organizador y vigilante del cumplimiento de la norma de la democracia representativa mexicana.

En este nuevo marco electoral y en plena crisis económica (1982), el candidato a la presidencia de la república por el PRI, Miguel de la Madrid Hurtado, cuyo lema era "la renovación moral de la sociedad", obtuvo el $70.99 \%$ de los votos (Elecciones en México 1979 -2015). Nada diferente en cuanto a porcentaje de votos obtenidos por sus predecesores. Además el PRI se quedó con todos los senadores, y sólo perdió dos distritos electorales a manos del PAN. Los otros partidos participarían en la Cámara de Diputados mediante el esquema de representación proporcional. Este hecho limitó las inconformidades sobre las irregularidades del proceso electoral y la Comisión Federal Electoral pasó sin pena ni gloria (Haddad, 2001).

Sin embargo, seis años después esta Comisión quedó en descrédito absoluto en las elecciones de 1988 que llevaron al triunfo del candidato prí́sta Carlos Salinas de Gortari sobre el ex prí́sta Cuauhtémoc Cárdenas. Las simulaciones y la dramaturgia aprendidas en épocas anteriores no fueron suficientes para justificar el fraude electoral conocido como "la caída del sistema" de conteo de los votos; algo parecido a un golpe de estado cibernético. Del modo que fuera, lo cierto es que se rompía cualquier proceso democrático que se pudiera estar llevando a cabo. No sólo eso, con esta acción se generaba antidemocráticamente el mayor gozne en la política económica y social del país, y la máxima transfiguración del partido gobernante que pasó del "nacionalismo revolucionario" derivado de la Revolución Mexicana, al "liberalismo social" de corte neoliberal (Muñoz, 2006). Una paradoja de la historia política de México.

Lo más grave de esta paradoja es que el neoliberalismo que se imponía con esta elección no correspondía a un proceso democrático, sino a un golpe de mano basado en la corrupción con las urnas. Los movimientos de protesta que le siguieron, el descrédito absoluto del árbitro electoral y la necesidad de legitimación, abrieron un nuevo capítulo de la interminable reforma electoral. Se estableció el Código Federal de Instituciones y Procedimientos Electorales (COFIPE) y se creó el Instituto Federal Electoral en sustitución de la Comisión Federal Electoral (Woldenberg, 2012). 
Se trataba ahora de una institución autónoma, con patrimonio y personalidad jurídica propios, responsable de organizar las elecciones, integrada por varias direcciones ejecutivas como el Registro Federal de Electores. Se dijo que el objetivo de su creación era contar con una institución imparcial que "diese certeza, transparencia y legalidad" a las elecciones federales. Se instauró además el Tribunal Federal Electoral, como última instancia jurídica en la materia. Con este cuerpo institucional, se terminaba en lo formal la supeditación de las instituciones electorales al gobierno, aunque en realidad sólo era en la forma, pues el Presidente del Consejo General del IFE siguió siendo el Secretario de Gobernación'.

Para las siguientes elecciones, a la naciente institución le tocó vivir una de los momentos más dramáticos de la historia política nacional. Primero, la insurrección zapatista que alteraba el entorno político electoral, y luego, el asesinato del candidato presidencial del PRI Luis Donaldo Colosio Murrieta, el 24 de marzo de 1994 en Tijuana, que empeoraba el panorama político aún más. Ya sea que se tratase de un asesino solitario, o que su muerte fuese dictada desde los más altos puestos de poder en México, lo cierto es que las elecciones se dieron en un ambiente de temor, silencio, y cierta resignación. La mejor prueba de ello fue la ausencia durante una parte importante del proceso electoral de 1994 del candidato del PAN, Diego Fernández de Ceballos, quien era considerado puntero después del debate entre los aspirantes presidenciales. El IFE y su presidente asumieron la actitud convencional de "aquí no pasó nada", y dieron los resultados de un proceso normal en favor del candidato priísta Ernesto Zedillo Ponce de León. El Secretario de Gobernación, encargado de la seguridad del país y presidente del IFE, Jorge Carpizo McGregor, sólo vio pasar el féretro de Colosio Murrieta (Cosío-Villegas, 1985).

Si la desconfianza en las instituciones electorales ya era grande con el fraude al candidato Cuauhtémoc Cárdenas y la imposición de Carlos Salinas de Gortari, ésta se agravó con el asesinato de Luis Donaldo Colosio. No sólo se acrecentaban las dudas sobre la limpieza de las elecciones, ahora la clase política temía que la contienda electoral estuviese definida por la supresión de los candidatos inconvenientes al nuevo sistema neoliberal.

La desconfianza llegó a tal nivel, que para el siguiente proceso electoral se tuvieron que tomar algunas medidas sustanciales como la sustitución del Secretario de Gobernación como Presidente del Consejo General del IFE por un académico con una trayectoria crítica al sistema, José Woldenberg (1997 a 2003). A él le tocó dirigir el proceso electoral del año 2000 en el cual el PRI perdió por primera vez la presidencia de la República a manos del PAN y su candidato Vicente Fox, pero sobre todo, sin que existiesen inconformidades significativas de los partidos participantes. Parecía que México iniciaba un periodo democrático ausente de simulaciones y de parcialidad arbitral (Méndez de Hoyos, 2006).

Sin embargo no fue así, en 2003, Luis Carlos Ugalde se convirtió en el presidente del órgano electoral y se esperaba que no tuviese problemas, luego de que el PAN y el presidente Fox presentasen sus blasones democráticos como su principal atributo. Lo cierto es que el electorado sólo esperaba eso de ellos, la instauración de la democracia electoral en el país. Pero el PAN y Vicente Fox tenían otros planes: impedir que el posible candidato de la izquierda a la presidencia de la República, Andrés Manuel López Obrador, llegase a las boletas electorales. Para ello se activaron una serie de componendas típicas de los priístas. Así, el PRD que apoyaba a López Obrador, quedó al margen del Consejo Federal Electoral; luego se exhibió la corrupción de dos colaboradores suyos en el Gobierno del Distrito Federal, y finalmente, un intento del desafuero en contra de Andrés Manuel López Obrador promovido por el propio presidente Fox, con apoyo del PRI y del PAN, por un incidente menor. Evidentemente se trataba de inhabilitar a uno de los contendientes más fuertes en las elecciones por venir. La reacción social en contra de los proponentes de tal estrategia valoró negativamente sus acciones a tal grado, que tuvieron que retractarse. No obstante, volverían a insistir en sus trucos el día de las elecciones (Woldenberg, 2012). 
En medio de dudas y de negociaciones urgentes entre el PRI y el PAN, el 2 julio del 2006 el candidato del PAN Felipe Calderón Hinojosa se convirtió en Presidente de México, con un margen de $\mathbf{0 . 5 6 \%}$ de los votos sobre Andrés Manuel López Obrador, según datos del IFE (2007). Lo apretado del resultado, la gran cantidad de anomalías y la necesidad de mantener la credibilidad en la democracia debieron llevar al IFE a repetir las lecciones, pero no lo hizo. En lugar de ello el instituto prefirió dar por válidos los resultados que el recién electo presidente Felipe Calderón resumió en su famosa frase: "Haiga sido como haiga sido". La oposición demandaba recontar los votos emitidos, lo cual no le fue concedido, y posteriormente el IFE y el TEPJF aprobaron destruir las boletas electorales. Así se abría una nueva decepción social sobre las aspiraciones democráticas plasmadas en el proceso electoral y en su árbitro en las elecciones de 2006.

Se volvió a aplicar la medicina habitual después de cada engaño electoral. Otra nueva reforma a la Ley Electoral y la remoción de Luis Carlos Ugalde de la presidencia del IFE junto con otros consejeros.

Un nuevo capítulo se abrió con el nombramiento de Leonardo Valdés Zurita como presidente del IFE. Académico respetado y con el propósito de obtener la confianza del electorado, se comprometió a promover una mayor participación ciudadana, equidad y civilidad en la contienda, transparencia en la organización y difusión de los resultados en el proceso electoral del 2009, una Controlaría General y la Unidad de Fiscalización para garantizar el manejo justo y honrado de los recursos de la institución (INE, 2020).

Pero la respuesta ciudadana en 2009 fue implacable: de los casi 78 millones de mexicanos inscritos en el padrón electoral, sólo votaron poco más de 34 millones de electores (Recursos electorales, 2020). El descrédito, la desconfianza y la parcialidad de los órganos electorales era la constante de un drama que parecía interminable. El abstencionismo en este tiempo y espacio de la vida política nacional, más que un símbolo de apatía era expresión de rebeldía. La no participación ponía en evidencia lo ilegítimo de los procesos electorales y por lo tanto de la democracia.

\subsection{La historia se repite}

Hacia las elecciones de 2012 el mismo IFE reconocía que "Ninguna de las elecciones organizadas por el IFE había arrancado con tantos cuestionamientos a la normatividad y a la autoridad electoral" (INE, 2020, 1). Las encuestas aplicadas sobre el particular mostraron que los ciudadanos en su gran mayoría desconfiaban del órgano electoral, es decir, del IFE. Tan dura fue la opinión pública en su contra, que el organismo en cuestión tuvo que lanzar un folleto titulado "Por qué no puede haber un fraude electoral".

Y sin embargo, lo hubo. Las elecciones de 2012 se caracterizaron por el manejo de grandes cantidades de dinero fuera de toda legislación para favorecer al candidato ganador a la Presidencia de la República, el Lic. Enrique Peña Nieto. Además de las prácticas propias del fraude electoral anterior, en esta ocasión resaltó la compra de las elecciones; es decir, dinero extra para la campaña, tarjetas bancarias Monex, tarjetas telefónicas pre pagadas y para las tiendas Soriana, Aurrerá, Chedraui y Walmart. A través de promotores profesionales, los votantes comprados eran acompañados a las casillas y se verificaba que el voto se emitiera de acuerdo a lo pactado (La jornada, 05/07/2012). En pocas palabras, las elecciones se manejaron en términos de mercado y los grupos del poder compraron a un presidente que tendría que pagar la cuenta cuando llegase a la silla presidencial (Castillo-García, G. 2012).

Nuevamente, para subsanar las grietas profundas de la democracia fallida se recetó una nueva reforma electoral. Desapareció el IFE y se creó en su lugar el Instituto Nacional Electoral, INE. A este organismo se le otorgaron más poderes, tendría capacidad de supervisar las elecciones 
locales, intervenirlas e incluso organizarlas (art. 41, base V, Apartado C) (INE, 2020). Esto limitaría la intervención de los gobernadores en las elecciones locales. También se le otorgó la posibilidad de organizar las elecciones internas de los partidos y la fiscalización de sus finanzas. Además estarían a su cargo las consultas populares (INE, 2020).

Al INE se le otorgaron también facultades policiales para investigar sobre el comportamiento correcto de los partidos y los medios de comunicación (art. 41, base III, apartado D), para integrar el expediente y someterlo al conocimiento y resolución del Tribunal Electoral del Poder Judicial de la Federación. Con el objetivo de aumentar su autonomía, se creó un comité técnico de evaluación de los candidatos a ser consejeros electorales, quien los calificaría antes de que fuesen votados por las dos terceras partes del Senado. Además, se creó el Servicio Profesional Electoral Nacional, debidamente reglamentado para que pudiese brindar un servicio eficaz y eficiente de manera permanente e independientemente del partido que estuviese en el gobierno.

Al Tribunal Electoral del Poder Judicial de la Federación (TEPJF) también se le ampliaron facultades sobre la propaganda, las campañas y acceso a los medios de comunicación (art. 41, base III, apartado D y art. 99, base IX) (INE, 2020).

\subsection{Una elección democrática que no se pudo evitar.}

Esta nueva institución se estrenó con el triunfo histórico en 2018 del candidato a Presidente de la República Andrés Manuel López Obrador por la coalición "Juntos haremos historia", sacando 30 puntos porcentuales de ventaja sobre su inmediato contendiente, Ricardo Anaya Cortés propuesto por la coalición "México al frente"; una coalición que reunía al partido más derechista de México (PAN) con el partido autodenominado de izquierda (PRD), que seis años antes había impulsado la candidatura del mismo López Obrador. El otro hecho histórico fue la caída estrepitosa del candidato oficialista José Antonio Meade Kuribreña, quien sólo alcanzó el $16.40 \%$ de los votos (INE, 2018) por la coalición "Todos por México".

El triunfo fue tan abrumador, que oscureció todas las irregularidades tradicionales (compra de votos, robo de urnas, etc.) que no dejaron de presentarse durante el proceso electoral y en las elecciones mismas, como fue el caso de Puebla.

\subsection{La parcialidad del árbitro continúa.}

En el caso de Puebla coincidieron las elecciones federales con las elecciones estatales, destacando por supuesto la elección del gobernador. Por la coalición "Por Puebla al frente" contendió Martha Érika Alonso Hidalgo, esposa del gobernador saliente, quien finalmente resultó la ganadora con $38.14 \%$ de los votos (IEE, 2018), mientras que Luis Miguel Gerónimo Barbosa Huerta, candidato de la coalición "Juntos haremos historia" obtuvo $34.04 \%$; es decir, una diferencia de sólo 4.04\%. El resultado se observaba anómalo, si se toma en consideración que en la mayoría de las encuestas se daba como ganador a Barbosa, que la votación que obtuvo fue $22.81 \%$ inferior a la que obtuvo en el Estado de Puebla el candidato presidencial nacional de la misma coalición, y $12.29 \%$ menor que la candidata a la presidencia municipal de Puebla, también por la misma coalición.

Pero además, el día de la jornada electoral en Puebla se caracterizó por la violencia en varias casillas. La prensa dio cuenta de tiroteos, robo de urnas y centros de manejo de boletas no autorizados por la institución electoral. Y de las 1106 denuncias nacionales ante la FEPADE, Puebla acaparó 127, el lugar con mayores anomalías a nivel nacional (El Financiero, 2018), más del doble que la Ciudad de México que tiene una población muchas veces mayor que el Estado de Puebla (El Economista, 2018). Ello ameritaba por lo menos una investigación exhaustiva por 
parte del INE con el fin de garantizar la certidumbre de los resultados, como se había comprometido en el mismo hecho de su fundación (IEEP, 2020).

Pero eso no ocurrió; los magistrados del Tribunal Electoral del Estado de Puebla (TEEP), por unanimidad, ratificaron la constancia de mayoría entregada a Martha Erika Alonso de la elección por la gubernatura del estado de Puebla, a pesar de que se demostró que había sido violada la cadena de custodia de las boletas electorales (Nexos, 2018; Camacho, M. 2018). Esta parcialidad del INE y de los tribunales electorales quedó evidenciada.

\subsection{Pregunta obligada: ¿Cómo se ha creado la dramaturgia electoral en México?}

Hacia 1946 se estaba conformando en México el bloque histórico nacional. Esta conformación correspondía adecuadamente a las estrategias de la posguerra caracterizada por la guerra fría, que proponía a todas las naciones aliadas un pacto o negociación de largo plazo entre empresarios y trabajadores, y en el marco de las políticas económicas keynesianas de pleno empleo que se estaban aplicando en las economías desarrolladas (Cisneros, 2015).

El Partido Revolucionario Institucional, con una clara estructura corporativista, representaba un bloque histórico en sí mismo. Los obreros y los campesinos existentes estaban cooptados a través de las centrales afiliadas al partido, y aunque su clase capitalista era débil, los inversionistas extranjeros y el estado cubrirían su papel en la esfera productiva, al mismo tiempo que el estado promovía el desarrollo de la clase empresarial nacional. En esa tesitura, el gobierno de Miguel Alemán habría de favorecer la formación de una burguesía nacional de cualquier forma, ya fuese su origen en el mismo PRI en la modalidad de políticos empresarios, como fue el caso del mismo presidente Miguel Alemán, ya sea que fuesen familias ex porfiristas, o concesionarios de empresas extranjeras. Todos ellos agrupados en las cámaras correspondientes, de comercio o de industria, además del fomento a pequeños y medianos empresarios que pasaron a engrosar las filas del sector popular del PRI. La Cámara de Diputados representaba dentro de los poderes del estado las proporciones que los sectores del PRI guardaban dentro del bloque, mientras la de senadores quedaba como prerrogativa presidencial para políticos vinculados a los empresarios y en función de sus intereses económicos y políticos. Por su parte, el presidente se erigía como el gran árbitro (Muñoz-Petrarca, 2006).

Pero el bloque histórico no sólo es de naturaleza política, sino que integra la política económica y la ideología prevaleciente. Así, el pacto gubernamental resultó congruente con la sustitución de importaciones y el desarrollo estabilizador en lo económico, como con el nacionalismo revolucionario en lo ideológico y el proceso de institucionalización en lo político. La democracia no era parte esencial del proceso, pues el bloque era lo suficientemente fuerte para imponerse nacionalmente y negociar con la disidencia si era necesario. Lo que resultaba indispensable era la simulación, para mostrarse ante Estados Unidos y el mundo como parte de la democracia occidental, lejanos del comunismo, y también para evitar una dictadura militar como era característico en América Latina. El bloque mostraba suficientemente la forma para encajar en un lugar privilegiado de la geopolítica mundial, y descollar con el estandarte de la "Doctrina Estrada" ante los problemas comprometedores de la guerra fría. La "dictadura perfecta", como diría el escritor Mario Vargas Llosa (Cisneros, 2015).

Sin embargo, el bloque entró en fase de deterioro desde los años setenta del siglo pasado, particularmente en la esfera económica, específicamente a causa del endeudamiento, pero también desde la esfera política por falta de la representatividad de fuerzas sociales emergentes. Entonces, el gobierno de Miguel de la Madrid fue una especie de periodo de transición, y durante el gobierno de Carlos Salinas de Gortari se inició de manera implacable el proceso de reestructuración general del bloque histórico. La idea era cambiar del bloque de sectores, económica y políticamente estructurados, y por añadidura antidemocráticos, a un pacto entre 
partidos de ciudadanos libres, racionales, cuyo objetivo sería la maximización de sus beneficios en el mercado económico y político (Cosío-Villegas, 1985).

Pero esta reestructuración terminó en una desfiguración estructural del bloque histórico anterior, con la exclusión progresiva de los trabajadores de la ciudad y del campo del ámbito económico, político e ideológico. En torno a un México neoliberal se establecieron acuerdos políticos y pactos entre partidos sin principios sociales; un pacto por intereses de grupo. De cualquier manera, en ambos momentos históricos permanecía una situación análoga: la escenificación, la dramaturgia de una democracia fingida.

Como puede deducirse, ni el bloque histórico anterior ni el pacto partidario resultaban afines a la democracia. En una democracia plena se defiende el proceso más allá de los intereses de los partidos políticos como grupo, y se ajusta la vida económica y política al programa del partido ganador. En una democracia simulada se sustituye la voluntad del electorado por los resultados convenientes para el grupo político en el poder y sus socios de la clase dirigente (Cisneros, 2015).

En el plano económico el pacto partidario impuso una política neoliberal que favoreció el cambio estructural, el libre comercio, el endeudamiento y el sometimiento del estado a los propósitos del mercado, las privatizaciones de las empresas del estado (incluyendo los bancos nacionalizados por López portillo), la deuda del FOBAPROA y las reformas estructurales. Particularmente la reforma minera y la energética legalizaron las entregas del gobierno mexicano neoliberal a particulares para fomentar el crecimiento de élites capitalistas de "clase mundial". Acordes con el pacto, en lo ideológico los llamados medios de comunicación proclamaron, bajo cualquier modalidad que se les presentase, desde el editorial más sesudo hasta la noticia más trivial, el pretendido pensamiento único: el pensamiento neoliberal (Haddad, 2001).

Si el presente y futuro se percibían neoliberales, resultaba pertinente entonces para la clase política pensar en un sistema bipartidista. EI PRI como partido liberal y el PAN como partido conservador, dirigiendo las coyunturas al estilo norteamericano, pero con el mismo manejo clasista y la orientación neoliberal. Durante un buen tiempo el PRD quedó excluido de esta aspiración, mientras sus candidatos a la presidencia fueron Cuauhtémoc Cárdenas y Andrés Manuel López Obrador, pero luego se incorporaría al pacto a través de su alianza con el PAN.

Sin embargo, algo no estaba en la agenda: la pérdida de confianza de algunos grupos de las élites mundiales en el liberalismo, con sus respectivas repercusiones económicas y políticas en todo el planeta, ni el hartazgo del electorado mexicano ante la corrupción y la desigualdad que encarnaba el sistema económico y político neoliberal mexicano. Todo ello se hizo visible en el apabullante triunfo de Andrés Manuel López Obrador en las elecciones de 2018.

\subsection{La falta un árbitro legítimo en el proceso de la democracia electoral.}

Si en la historia política de México la democracia representativa sigue en proceso con un futuro relativamente incierto, se debe en gran medida a la gestión del árbitro electoral, puesto que él es el vértice de la confianza en las elecciones y no se ha mostrado confiable a ojos de la ciudadanía. Para el avance democrático se requiere un equipo de personas confiables, imparciales y realmente independientes de los grupos de interés, que cuente con, o adquiera, la confianza de los electores. No basta la legalidad que se tiene, se requiere sobre todo la legitimidad que otorga la ciudadanía.

Desafortunadamente, en los hechos puede observarse que la imparcialidad, la independencia y la legitimidad no se han logrado. Si se hace una revisión de las influencias políticas sobre los consejeros del INE hasta el mes de abril de 2020, se observa que cinco de los diez consejeros están relacionados con el PRI, tres con el PAN, uno con el PRD, y uno se le identifica con el Partido Nueva Alianza (El Economista, 2018). Por si fuera poco, el consejo ha demostrado estar 
lejos de ser un actor neutral. Esto se observa en los resultados que ha brindado en términos de democracia, históricamente y en el caso Puebla, así como su actitud permisiva respecto al dinero ilegal que ha sido usado en las pasadas campañas electorales. No puede pasarse por alto el caso reciente de la elección del Secretario Ejecutivo del INE, realizado a deshoras de la noche, fuera de toda consideración, y que muestra al INE como un organismo ajeno la transparencia.

En la coyuntura actual, si bien los consejeros electorales están relacionados con los partidos políticos, al menos sería importante equilibrar sus posiciones políticas. Con el triunfo de la coalición "Juntos haremos historia" y la posibilidad real de que ésta pudiera elegir a los cuatro consejeros que de acuerdo a la ley serían remplazados, se esperaba que estos fuesen afines a los partidos que conforman dicha coalición en virtud de que tenían la capacidad de hacerlo. Estos partidos habían sido excluidos de la conformación anterior del consejo, y, en caso de que ahora participaran en él, equilibrarían su composición para evitar los comportamientos tendenciosos antes aludidos.

Sin embargo, ante tal perspectiva de equilibrar la composición del consejo, los partidos derrotados, organismos gubernamentales y asociaciones civiles ligadas al régimen anterior, entraron en pánico. Denunciaron imposiciones del gobierno aun cuando ellos han sido quienes han impuesto a los consejeros haciendo a un lado los procedimientos democráticos transparentes. Finalmente, los cuatro nuevos consejeros parecen haber seguido el camino del acuerdo político entre partidos, y sobre todo, se mantiene la estela de la desconfianza en dicho consejo por parte de los electores (Redacción Animal Político, 2020).

La necesidad de un árbitro electoral con la mayor legitimidad posible es fundamental para el avance de la democracia representativa en México, y para ello habría que plantearse, por ejemplo, la posibilidad de que los consejeros sean elegidos o removidos por el voto universal, directo y secreto de los ciudadanos. Sería lo más congruente con quienes organizan la democracia electoral

\section{La perspectiva de la democracia en México}

La perspectiva de la democracia en México es sin duda compleja. Se trata de un país que sigue aspirando a la libertad, a la igualdad, a la fraternidad, a la democracia plena. Pero esta búsqueda de ser un mejor país ha enfrentado una histórica situación de desigualdad social, económica y política, tanto en su funcionamiento como en los ordenamientos jurídicos que no se cumplen, o que se han hecho a modo para legalizar la desigualdad y el despojo, como el hecho de volver pública una deuda privada de banqueros, o las reformas estructurales para privatizar los recursos naturales de la nación, además de los servicios educativos y de salud. Situación que sólo recientemente se empieza a enfrentar desde el gobierno federal a partir de diciembre de 2018, en medio de ataques y presiones permanentes por parte de quienes se beneficiaron con el régimen anterior.

En cuanto al árbitro electoral, dado que cuenta con una estructura jurídica y política progresista, el ordenamiento formal parece ser suficiente desde hace tiempo para cubrir el expediente legal de la democracia. Incluso el modelo organizativo del Instituto Federal Electoral (IFE) puede ser considerado de vanguardia y ha sido ejemplo para otros países. Desafortunadamente sólo en la forma, en la dramaturgia política. En los hechos vivimos una democracia imperfecta, todavía actúan grupos políticos que viven de la simulación, con un árbitro electoral que ha mostrado reiteradamente su parcialidad y su vinculación con el viejo régimen a través de sus dirigentes (Woldenberg, 2012). 
Ciertamente, constituir un árbitro imparcial expuesto permanentemente a la sociedad, y sujeto a la remoción como forma de evaluar su comportamiento en las elecciones a todos los niveles, federales y locales, no lo es todo, pero podría significar un gran avance.

Por ello, si en el Tribunal Electoral del Poder Judicial de la Federación y con los consejeros electorales que conforman el Consejo General del Instituto Nacional Electoral se lograra un nuevo equilibrio en su composición, de acuerdo a los cambios políticos del país, esto podría abonar al avance buscado, pues inhibiría la red de complicidades con el viejo régimen que mantiene estancada a la democracia electoral en México. De lo contrario, el horizonte de la democracia realmente representativa parece inalcanzable.

Vivimos tiempos de cambio en todo el mundo. Brindar confianza de las instituciones a sus ciudadanos es una de las vertientes de esos cambios, pero tendrán que incluir el fin de la desigualdad extrema, impedir la corrupción y terminar con la simulación democrática. Para ello son necesarios dos factores clave: Una mayor conciencia política y participación cotidiana de los ciudadanos en las decisiones públicas, y la colaboración real de los grandes empresarios en este cambio.

La mayoría de los ciudadanos mexicanos ya mostró su decisión de cambio en las pasadas elecciones presidenciales de 2018, y está cada vez más atenta de los eventos políticos que les pueden favorecer o perjudicar. Si las clases dirigentes aceptan este cambio hacia un enfoque sustentable de sus negocios en favor de la equidad, la legalidad y el bienestar de todos, y no apoyan campañas políticas golpistas como las que existen hoy día, podremos entrar a una fase de cultura política y social constructiva, donde los problemas de cualquier tipo podrán ser resueltos en función de los intereses colectivos de todos los mexicanos. Serían vigentes por primera vez en México los principios de libertad, igualdad y fraternidad.

Para concluir esta perspectiva, aún con la incertidumbre, vale la pena considerar el valor y significado que tiene el anuncio que se hizo el pasado 5 de octubre de 2020 en el Palacio Nacional acerca de un plan de trabajo conjunto, con proyectos específicos, que se firmó entre el actual gobierno y los dirigentes empresariales mexicanos para reactivar la economía y los empleos, y así superar la crisis sanitaria y sus efectos económicos que afectaron seriamente a toda la población (Expansión, 2020). Sobre este acuerdo económico-social del gobierno con la clase dirigente mexicana podría sustentarse un avance de los procesos democráticos. La tarea es complicada por los antecedentes expuestos, pero esto puede significar un buen primer paso.

\section{Referencias bibliográficas y electrónicas}

Bobbio, N. et al. (2005). Diccionario de política. México: Siglo XXI.

Camacho, M. (2018). "Denuncia Barbosa que la votación se alteró de origen a favor de MEAH”. La Jornada, 07/26/2018. Consultado 0 el https://www.lajornadadeoriente.com.mx/puebla/denuncia-barbosa/

Castillo-García, G. (2012). "Bajo la lupa, Soriana, Monex y dos empresas". La Jornada, (07/12/2012). Consultado https://www.jornada.com.mx/2012/07/12/politica/007n2pol

Centro de Estudios de la Democracia y Elecciones (CEDE, s/f). http://cede.izt.uam.mx:8089/cedeSys/faces/cede/records.xhtml?tableld=25

Cisneros, J. (2015). Un mundo falso. Notas sobre sus constructores actuales. Tenerife, España: Sociedad Latina de Comunicación Social. 
Chen Y. (2020) "Modern Market Economy". En: New Economic Engine: Effective Government and Efficient Market. China Academic Library. Springer: Singapore. https://doi.org/10.1007/978-98115-2922-1 6

Cosío-Villegas, D. (1985). Breve historia de México. México: El Colegio de México.

Doyle, W. (2018). The Oxford History of the French Revolution. Oxford: Oxford University Press.

El Economista (2018). "Puebla, el estado con más denuncias ante la FEPADE" /07/02/2018. Consultado el 07/21/2020. https://www.eleconomista.com.mx/politica/Puebla-el-estado-con-masdenuncias-ante-la-FEPADE-20180702-0023.html

El Economista (2020). "INE, sin cuatro consejeros y ante una pandemia" 04/20/2020. Consultado el 07/23/2020. https://www.eleconomista.com.mx/politica/INE-sin-cuatro-consejeros-y-ante-unapandemia-20200420-0156.html

Elecciones en México 1979 -2015. http://www.historiaelectoral.com/mexico.html

El Financiero (2018). "Elecciones 2018. Fepade atiende 74 denuncias electorales". 01/07/2018. México https://www.elfinanciero.com.mx/elecciones-2018/fepade-atiende-74-denunciaselectorales

Expansión (2020). "Empresarios y gobierno invertirán 297,000 mdp en 39 proyectos de infraestructura". 05.10.2020 México. https://expansion.mx/empresas/2020/10/05/amlo-ippresentan-plan-de-reactivacion-39-proyectos-297-mdp

Gramsci, A. (1981). Cuadernos de la cárcel. México: Ediciones Era.

Habermas, J. (2014). The Future of Human Nature. Hoboken: John Wiley \& Sons

Habermas, J. (1993). El discurso filosófico de la modernidad. Madrid: Taurus

Habermas, J. (1987). Teoría de la acción comunicativa [1981]. Madrid: Taurus.

Haddad, P. (2001). Los valores de la democracia: historia del sufragio en México. México: UJAT

Handbook on Electoral Management Design (2014). http://www.eods.eu/library/IDEA.ElectoralManagement-Design.pdf

Instituto Estatal Electoral-Puebla, (IEEP, 2018). Proceso Electoral Estatal Ordinario 2017-2018. Concentrado de Cómputo Final de la Elección de Gubernatura.

https://www.ieepuebla.org.mx/2018/resultados/Finales Gubernatura anexo.pdf

IFE (2007).

https://portalanterior.ine.mx/documentos/Estadisticas2006/presidentet/nac.html

INE $(2020,1)$.

https://portalanterior.ine.mx/archivos3/portal/historico/contenido/interiores/Detalle IFE te respond e-id-bece9962ff108310VgnVCM1000000c68000aRCRD/

INE

https://portalanterior.ine.mx/archivos3/portal/historico/contenido/menuitem.cdd858023b32d5b7787 $\underline{\mathrm{e} 6910 \mathrm{~d} 08600 \mathrm{a} 0 /}$

INE (2018) https://computos2018.ine.mx/\#/presidencia/nacional/1/1/1/1

Instituto Electoral del Estado de Puebla, (IEEP, 2020). Elecciones Estatales de Puebla, Gubernatura 2018. Consultado el 07/18/2020. https://preppuebla2018.mx/gubernatura

INE (2018) https://computos2018.ine.mx/\#/presidencia/nacional/1/1/1/1 
Kates, S. (2011) Free Market Economics: An Introduction for the General Reader. Cheltenham: Edward Elgar Publishing.

Lewis, P. (2006) Authoritarian Regimes in Latin America: Dictators, Despots, and Tyrants. Lanham: Rowman \& Littlefield Publishers.

Méndez de Hoyos, (2006). Transición a la Democracia en México: competencia Partidista y Reformas electorales 1977- 2003. México: Fontamara.

Muñoz Petraca, V. (2006) Partido Revolucionario Institucional 1946-2006. México: Editorial Siglo XXI.

Murillo, F. (1990). Estudios de sociología política. Madrid: Tecnos.

Nexos, revista (2018) 10/12/2018. https://eljuegodelacorte.nexos.com.mx/?p=9348

Portelli, H. (1977). Gramsci y el bloque histórico. México: Siglo XXI.

Recursos electorales, (2020). http://recursoselectorales.org/mx/diputados.php?election=2009

Animal Político (2020) "Diputados aprueban a los 4 nuevos consejeros del INE; estos son sus perfiles". Consultado el 07/30/2020. https://www.animalpolitico.com/2020/07/nuevos-consejerosine-votacion-morena-diputados/

Reyna, J. L. (1993) “Las elecciones en el México Institucionalizado, 1946 - 1976”. En: González Casanova (1993) Las Elecciones en México: evolución y perspectivas. México: Siglo XXI.

Servín, E. (2002) "Las elecciones presidenciales de 1952: Un intento de cambio democrático". En: Estudios de Historia Moderna y Contemporánea de México. Martha Beatriz Loyo (editora). México: Universidad Nacional Autónoma de México, Instituto de Investigaciones Históricas, vol. 23, 2002, pp. 179-205.

The Economist, Intelligence Unit (2019). En: Democracy Index 2018: Me too? Political participation, protest and democracy. https://bit.ly/3hbH6DJ

Weber, M. (1997). Sociología de la religión. Madrid: Istmo.

Woldenberg, J. (2012). Historia Mínima de la Transición Democrática de México. México: El Colegio de México.

\section{NOTAS}

\footnotetext{
'Personajes influyentes del partido de Estado comandaron a la máxima institución electoral, a saber: Fernando Gutiérrez Barrios (1990 - 1992); Patrocinio González Garrido (1992 - 1993); Jorge Carpizo McGregor (1994); Esteban Moctezuma (1995) y Emilio Chuayffet Chemor (1995 - 1996).
} 